\title{
Identifikasi Jenis dan Karakteristik Lempung di Perbukitan Jiwo, Bayat, Klaten dan Arahannya sebagai Bahan Galian Industri
}

\author{
Tri Winarno*, Anis Kurniasih, Jenian Marin, Istiqomah Ari Kusuma \\ Departemen Teknik Geologi, Fakultas Teknik,Universitas Diponegoro, \\ Jl. Prof. Soedarto, SH, Kampus Tembalang, Semarang, Indonesia 50275
}

\begin{abstract}
Abstrak
Perbukitan Jiwo di Bayat, Klaten, merupakan suatu inlier dari batuan Pra-Tersier dan Tersier di sekitar endapan Kuarter. Perbukitan Jiwo tersebut mempunyai kondisi geologi yang kompleks. Salah satu batuan yang menyusun Kompleks Perbukitan Jiwo adalah batuan metamorf berupa sekis dan filit. Batuan metamorf tersebut telah mengalami pelapukan yang intensif, ditandai dengan hadirnya soil yang berwarna merah. Hasil pelapukan batuan metamorf tersebut berupa lempung yang telah dimanfaatkan oleh penduduk sekitar sebagai bahan pembuatan gerabah. Tujuan dari penelitian ini adalah untuk mengidentifikasi jenis mineral lempung di Perbukitan Jiwo dan juga karakteristik fisik dan kimia dari mineral lempung tersebut untuk melihat potensi lempung untuk bidang industri. Metode analisis yang digunakan dalam penelitian ini adalah dengan metode analisis XRD untuk mengetahui karakteristik mineralogi lempung, analisis XRF untuk mengetahui kandungan kimia lempung dan metode analisis fisik untuk mengetahui karakteristik fisik dan megaskopis lempung. Berdasarkan hasil analisis, jenis mineral lempung yang dijumpai adalah kaolinit, smektit dan serisit. Lempung tersebut dapat dimanfaatkan sebagai bahan pembuatan gerabah. Lempung tersebut tidak dapat digunakan dalam industri lain seperti farmasi, kosmetik dan kertas karena tidak memenuhi persyaratan kadar kimia.
\end{abstract}

Kata kunci: Perbukitan Jiwo; Bayat; Mineral Lempung; XRD; XRF; Manfaat Lempung

\begin{abstract}
[Title: Identification of Clay Minerals Type and Characteristics at Jiwo Hills, Bayat, Klaten and the Potential Use as Industrial Materials] Jiwo hills in Bayat, Klaten, is an inlier of Pre-Tertiary rocks and Tertiary rocks surrounded by Quaternary sediment with a complex geological relationship. Jiwo Hills Complex is comprised of metamorphic rocks of schist and phyllite. The metamorphic rocks have undergone intensive weathering, characterized by the presence of red clay soil. The process resulted in clays that has been used by the local people as pottery materials. The purpose of this study was to identify the type of clay minerals in the Jiwo hills, as well as to to determine the physical and chemical characteristics of the clay minerals to assess the potential value for industrial materials. The analytical method used in this research was XRD analysis to determine mineralogy characteristics of clays, XRF analysis to determine the chemical content of clay and physical analytical methods to determine the physical characteristics of clay. The analysis results showed that minerals found in were Kaolinite, Smectite and Sericite. The clay is suitable for pottery material, however, it can not be used in pharmacy, cosmetics and paper industry due to the chemical content which does not meet the requirements.
\end{abstract}

Keywords: Jiwo hills; Bayat; clay minerals; XRD; XRF; benefits of clay

\section{Pendahuluan}

Bayat adalah sebuah kota kecamatan yang termasuk dalam wilayah Kabupaten Klaten, Provinsi Jawa Tengah. Daerah Bayat tepatnya terletak sekitar 14 km di sebelah selatan Kota Klaten. Di daerah Bayat terdapat perbukitan yang terletak di antara Kota Klaten dan Pegunungan Selatan, yang dikenal dengan nama

\footnotetext{
${ }^{*}$ Penulis Korespondensi.

E-mail: triwingeo@gmail.com
}

doi:10.14710/teknik.v38n2.12942
Pegunungan Jiwo.

Daerah Perbukitan Jiwo merupakan daerah yang relatif sempit namun memiliki kondisi geologi yang kompleks. Semua jenis batuan dapat dijumpai di daerah ini. Salah satu batuan yang tertua di Jawa yang berupa kompleks batuan metamorf juga dapat dijumpai.

Batuan metamorf yang ada di kompleks Perbukitan Jiwo tersebut sebagian dijumpai dalam kondisi lapuk. Bahkan di beberapa tempat telah menjadi lempung yang oleh warga setempat dimanfaatkan sebagai bahan untuk pembuatan gerabah Sampai saat ini belum ada penelitian yang secara khusus membahas tentang Copyright @ 2017, TEKNIK, p-ISSN 0852-1697, e-ISSN: 2460-9919 
lempung hasil ubahan dari metamorf tersebut. Penelitian yang dilakukan mengenai kerajinan gerabah di sekitar Perbukitan Jiwo, masih berupa penelitian tentang aspek sosial budaya dan ekonomi dari keberadaan industri gerabah tersebut. Penelitian itu diantaranya adalah penelitian Hastuti (2009), yang meneliti tentang usaha industri kerajinan gerabah di Desa Melikan, Kecamatan Wedi, Kabupaten Klaten.

Lempung di kompleks Perbukitan Jiwo ini merupakan potensi yang sumber daya alam yang perlu digarap. Dengan pertimbangan nilai potensi yang ada, maka perlu dilakukan penelitian tentang lempung tersebut. Dengan penelitian ini diharapkan dapat diketahui jenis dan karakteristik lempung di Perbukitan Jiwo. Data tentang jenis dan karakteristik lempung ini dapat dimanfaatkan untuk meningkatkan nilai guna lempung, selain sebagai bahan gerabah.

\section{Bahan dan Metode}

Pengumpulan data mengenai karakteristik lempung di daerah penelitian, dilakukan dengan melakukan observasi lapangan dan analisis laboratorium. Pengamatan megaskopis dilakukan terhadap sampel untuk mengetahui sifat fisik lempung. Hal ini dilakukan dengan analisis warna, ukuran butir, sifat lempung jika dicampur air.

Mineralogi lempung diketahui dengan analisis $X$ ray Diffractometry (XRD) terhadap 3 sampel tanah lempung hasil lapukan batuan metamorf. Langkah preparasi dilakukan dengan memisahkan sampel tanah lempung dan mengambil fraksi lempung saja dengan cara pemisahan sentrifugal. Analisis XRD dilakukan dalam tiga perlakuan, yaitu air-dried, ethylene glycolated, dan heated pada $550^{\circ} \mathrm{C}$ secara berurutan.

Analisis geokimia berupa analisis $X$-Ray Fluorescence $(X R F)$ juga dilakukan terhadap sampel lempung. Analisis ini dilakukan untuk menganalisis elemen-elemen utama dan unsur-unsur jejak beserta konsentrasinya pada endapan kaolin dengan menggunakan metode spektrometri. Saat ini XRF merupakan metode analisis yang paling sering digunakan dalam penentuan unsur mayor dan unsur jejak pada sampel batuan. Dibandingkan dengan metode analisis geokimia lain, analisis XRF ini memiliki kemampuan deteksi lebih peka pada unsur terendah namun tidak dapat mendeteksi unsur yang lebih ringan dari $\mathrm{Na}$ yang memiliki nomor atom 11 (Rollinson, 1993).

\section{Hasil dan Pembahasan \\ 3.1. Sifat Fisik Lempung}

Lempung yang dijumpai di Perbukitan Jiwo, Bayat mempunyai sifat fisik: berwarna cokelat kemerahan; berukuran sangat halus; mudah rekah dalam kondisi kering, namun sangat liat/lengket dalam kondisi basah; mudah dibuat menjadi bentuk yang diinginkan dan bersifat elastis (tidak mudah patah dan pecah) dan di lapangan, lempung tersebut sering bercampur dengan pecahan kuarsit yang merupakan urat di dalam batuan metamorf yang merupakan batuan asal lempung tersebut (Gambar 1).

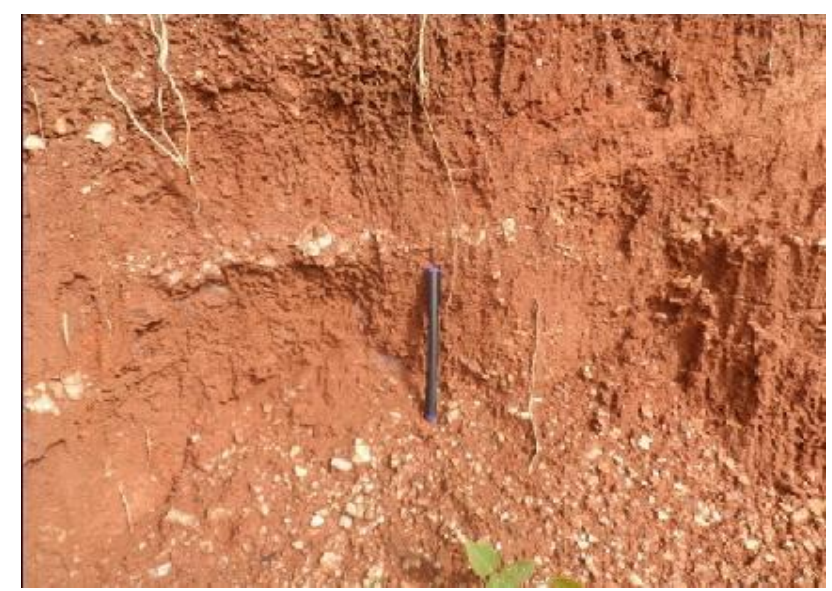

Gambar 1. Kenampakan lempung di Gunung Konang, Komplek Perbukitan Jiwo, Bayat

\subsection{Mineralogi Lempung}

Analisis XRD dilakukan dengan tahapan yang dimulai dari pemisahan fraksi lempung yang diperoleh dari agregat tanah lempung. Pemisahan dilakukan dengan metode sentrifugasi dengan meletakkan fraksi lempung pada kaca preparat dan menganginanginkannya di udara terbuka (air-dried) sebelum ditembak dengan XRD. Sampel ditembak kembali setelah diperlakukan dengan etilen glikol (ethylene glycolated). Terakhir, sampel ditembak kembali setelah dipanaskan hingga suhu $550^{\circ} \mathrm{C}$ (heated $550^{\circ} \mathrm{C}$ ). Perlakuan tambahan tersebut bertujuan untuk mengidentifikasi spesies mineral lempung tertentu yang tidak muncul pada perlakuan air-dried.

Analisis XRD dengan menggunakan tiga metode tersebut dilakukan terhadap semua sampel, kecuali sampel lempung dari Pager Jurang, yang hanya mendapat dua perlakuan, yakni air-dried dan ethylene glycolated. Hasil analisis lempung dengan metode XRD menunjukkan bahwa tanah lempung tersusun oleh mineral lempung jenis kaolinit, serisit, dan smektit.

Hasil analisis sampel lempung dari Pager Jurang menunjukkan kandungan mineral Smektit dan Kaolinit (Gambar 2), sedangkan sampel dari Gunung Sari, setelah melalui tiga perlakuan, hanya menunjukkan komponen Kaolinit (Gambar 3). Hasil analisis sampel lempung dari Gunung Konang dengan menggunakan metode air-dried dan ethylene glycolated menunjukkan adanya mineral Kaolinit dan Smektit. Setelah melalui perlakuan Heated $550^{\circ} \mathrm{C}$, terdapat mineral lempung lain yaitu Serisit (Gambar 4). Hasil analisis sampel lempung dari Gunung Gajah dengan menggunakan metode air-dried dan ethylene glycolated menunjukkan adanya kandungan Smektit dan Kaolinit. Pada perlakuan heated $550^{\circ} \mathrm{C}$, 
Teknik, 38 (2), 2017, 67

sampel ini menunjukkan kandungan Kaolinit saja (Gambar

$5)$.

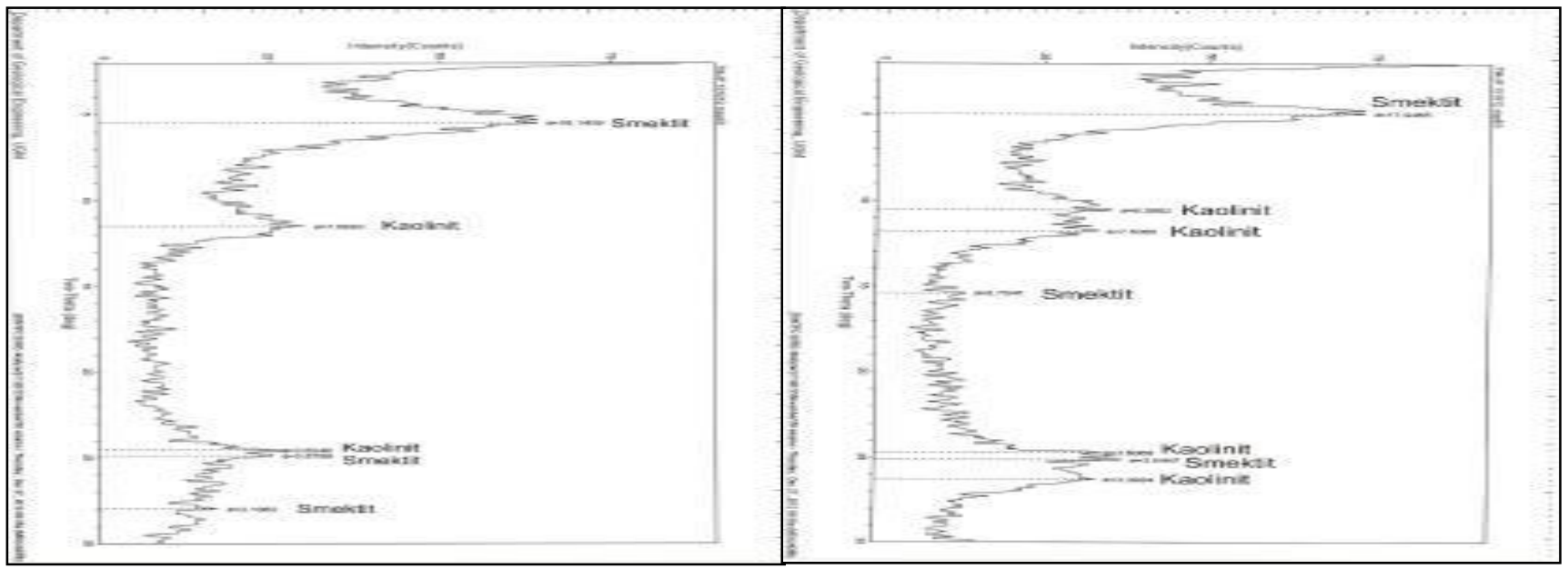

Gambar 2. Hasil analisis mineral lempung sampel Pager Jurang dengan dua metode XRD $(\mathrm{AD}=$ Air dried, $\mathrm{EG}=$ Ethylene glycolated $)$, mengidentifikasi keberadaan mineral lempung Kaolinit dan Smektit

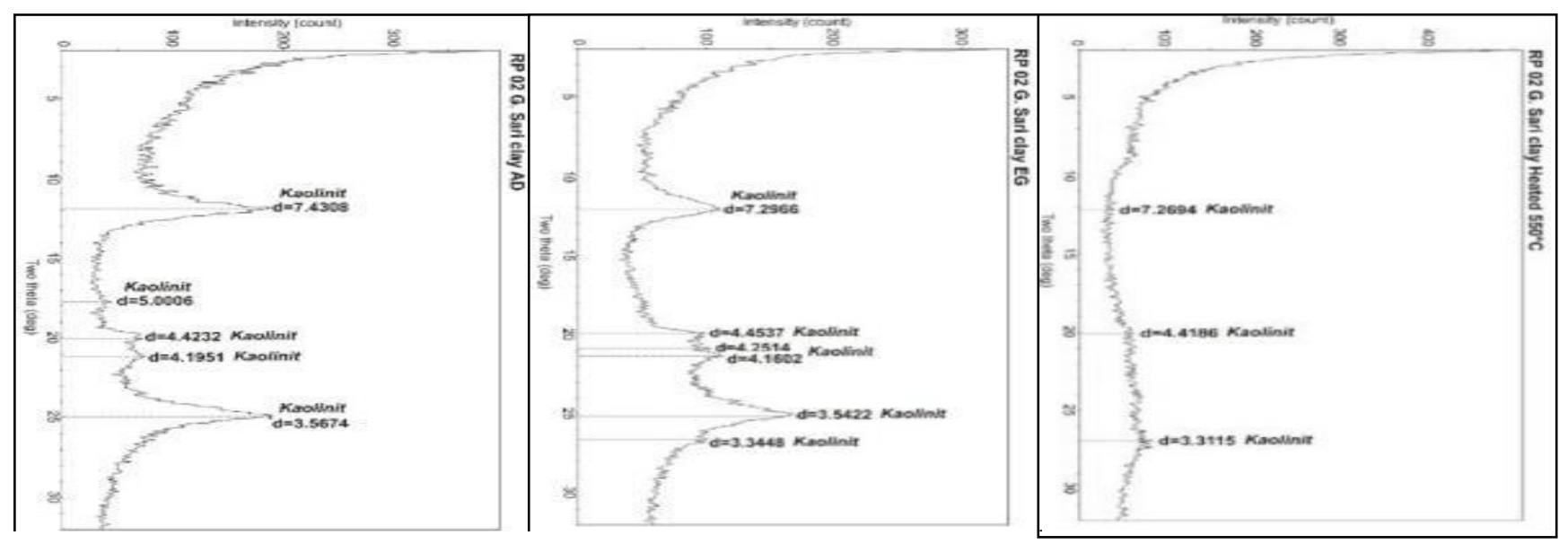

Gambar 3. Hasil analisis mineral lempung sampel G. Sari dengan tiga metode $\mathrm{XRD}(\mathrm{AD}=$ Air dried, $\mathrm{EG}=$ Ethylene glycolated, dan heated $550^{\circ} \mathrm{C}$ ), ketiganya mengidentifikasi satu jenis mineral lempung yaitu Kaolinit

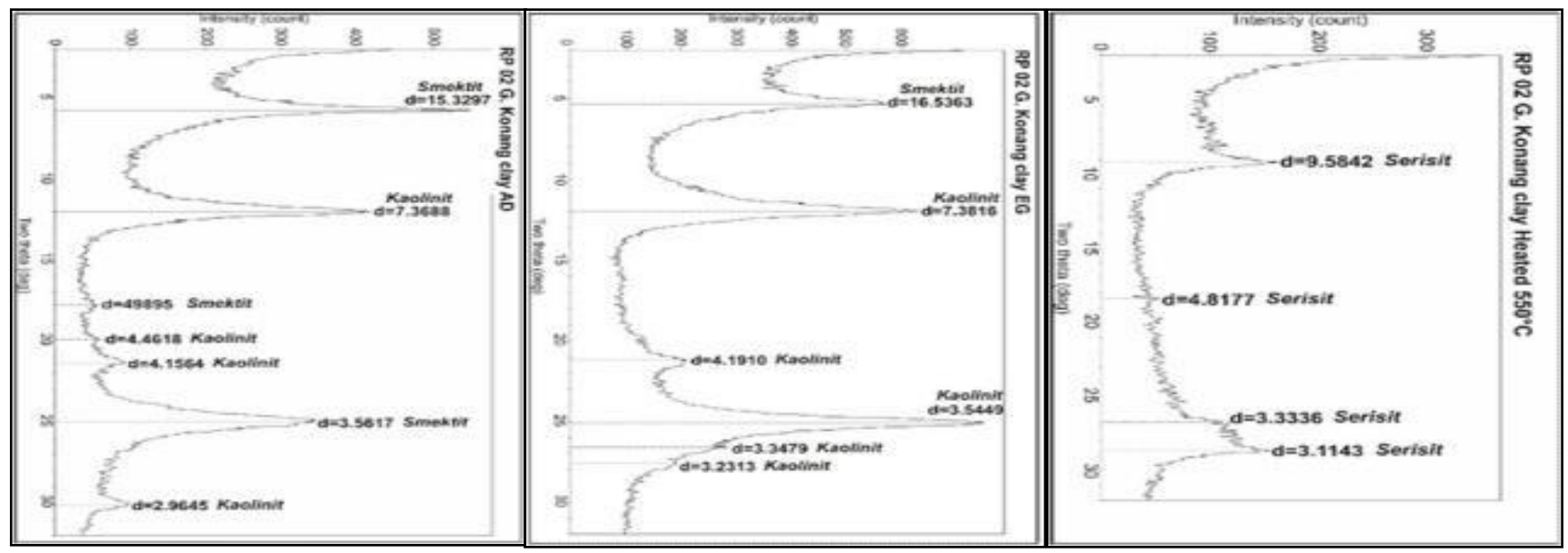

Gambar 4. Hasil analisis mineral lempung sampel G. Konang dengan tiga metode XRD (AD = Air dried, $\mathrm{EG}=$ Ethylene Glycolated, dan heated $550^{\circ} \mathrm{C}$ ), mengidentifikasi keberadaan mineral lempung jenis Kaolinit, Smektit, dan Serisit 
Teknik, 38 (2), 2017, 68

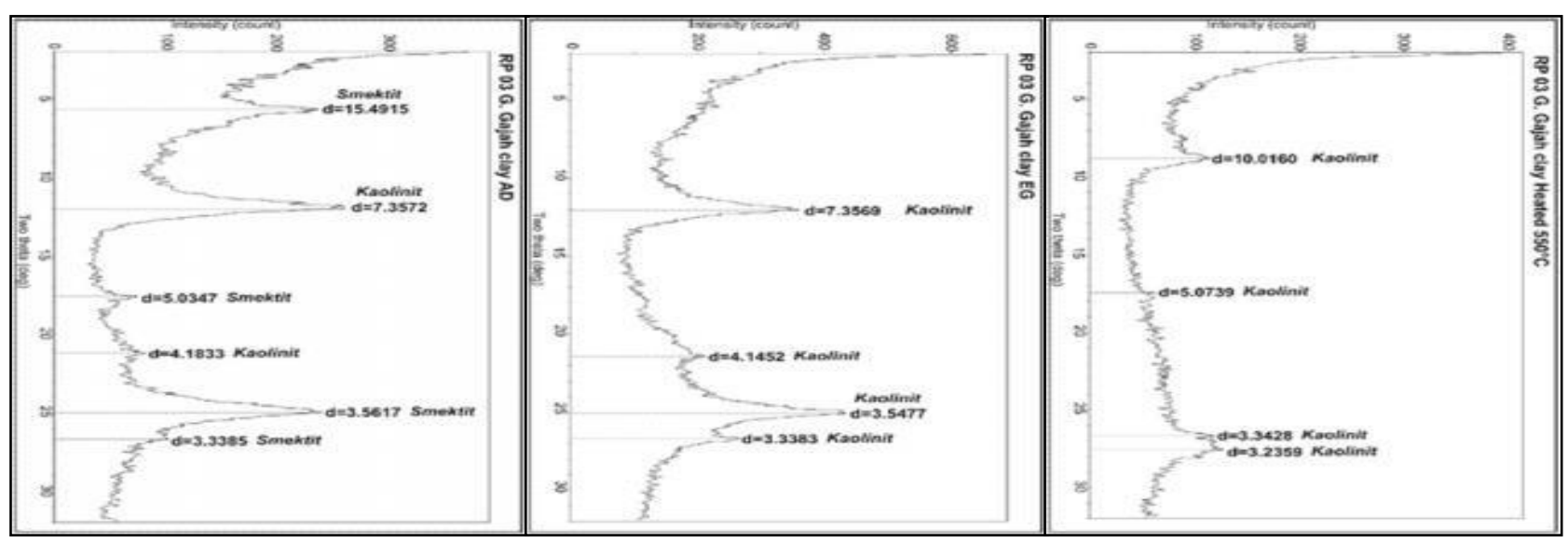

Gambar 5. Hasil analisis mineral lempung sampel G. Gajah dengan tiga metode XRD (AD = Air dried,

$\mathrm{EG}=$ Ethylene glycolated , dan heated $550^{\circ} \mathrm{C}$ ), mengidentifikasi keberadaan mineral lempung jenis Kaolinit dan Smektit

\subsection{Geokimia Lempung}

Komposisi kimia lempung dapat diketahui dengan analisis XRF. Analisis ini menghasilkan keluaran persentase unsur oksida utama yang menyusun lempung. Analisis XRF dilakukan di Laboratorium Pusat Teknologi Bahan Galian Nuklir-Badan Tenaga Nuklir Nasional (PTBGN-BATAN). Hasil analisis tersebut dapat dilihat pada Tabel 1.

Tabel 1. Komposisi Kimia Lempung pada daerah penelitian

\begin{tabular}{clcccc}
\hline NO & Oksida & $\begin{array}{c}\text { Lempung } \\
\text { Pagar } \\
\text { Jurang } \\
(\boldsymbol{\%})\end{array}$ & $\begin{array}{c}\text { Lempung } \\
\text { Gunung } \\
\text { Sari } \\
(\boldsymbol{\%})\end{array}$ & $\begin{array}{c}\text { Lempung } \\
\text { Gunung } \\
\text { Konang } \\
(\boldsymbol{\%})\end{array}$ & $\begin{array}{c}\text { Lempung } \\
\text { Gunung } \\
\text { Gajah } \\
(\boldsymbol{\%})\end{array}$ \\
\hline 1 & $\mathrm{SiO}_{2}$ & 49,69 & 43,43 & 37,19 & 45,36 \\
2 & $\mathrm{Al}_{2} \mathrm{O}_{3}$ & 22,03 & 28,98 & 19,14 & 22,45 \\
3 & $\mathrm{Fe}_{2} \mathrm{O}_{3}$ & 7,69 & 11,56 & 13,19 & 9,45 \\
4 & $\mathrm{TiO}_{2}$ & 0,86 & 1,13 & 1,30 & 0,92 \\
5 & $\mathrm{CaO}$ & 0,36 & 0,29 & 0,82 & 0,77 \\
6 & $\mathrm{MgO}$ & 1,21 & 1,38 & 0,33 & 1,12 \\
7 & $\mathrm{~K} 2 \mathrm{O}$ & 2,84 & 0,07 & 0,26 & 0,39 \\
8 & $\mathrm{Na} 2 \mathrm{O}$ & 0,58 & 0,06 & 0,16 & 0,91 \\
9 & $\mathrm{P} 2 \mathrm{O} 5$ & 0,13 & 0,051 & 0,14 & 0,14 \\
10 & $\mathrm{MnO}$ & 0,066 & 0,076 & 0,17 & 0,19 \\
11 & $\mathrm{Cr} 2 \mathrm{O}_{3}$ & 0,043 & 0,05 & 0,02 & 0,042 \\
\hline
\end{tabular}

\subsection{Saran Penggunaan Lempung}

Berdasarkan identifikasi dengan XRD, jenis mineral lempung yang terdapat pada sampel lempung di Perbukitan Jiwo adalah Kaolinit, Smektit dan Serisit. Mineral lempung tersebut secara umum dapat digunakan dalam industri keramik/gerabah, industri farmasi dan kosmetik, industri kertas, industri karet dan lain-lain. Penggunaan lempung dalam berbagai bidang tersebut harus memenuhi persyaratan kadar kimia tertentu sesuai dengan spesifikasi yang disyaratkan dalam berbagai industri.

a. Sebagai bahan baku gerabah

Jenis mineral lempung yang paling umum digunakan sebagai bahan baku gerabah adalah Kaolin. Lempung tersebut harus cukup plastis dan mudah dibentuk, mudah dibengkokkan serta tidak mudah patah (Smoot, 1961). Smektit perlu ditambahkan dalam bahan gerabah karena mempunyai sifat dapat menambah keplastisan lempung sehingga lebih mudah dibentuk. Lempung di Perbukitan Jiwo tersusun oleh mineral Kaolinit dan Smektit, dan mempunyai sifat fisik yang memenuhi persyaratan untuk dijadikan sebagai bahan baku gerabah, sehingga dapat direkomendasikan sebagai bahan baku gerabah.

Kelebihan lempung di Perbukitan Jiwo ini adalah kandungan Oksida Besi $(\mathrm{Fe} 2 \mathrm{O} 3)$ yang relatif tinggi yaitu berkisar antara 7,67-13,19\% (Tabel 1). Kandungan ini terlihat dari warna lempung yaitu cokelat kemerahan. Warna cokelat kemerahan ini menjadi ciri khas dari gerabah Bayat.

Kelemahan lempung di Perbukitan Jiwo adalah banyaknya fragmen Kuarsit dalam berbagai ukuran, sehingga membuat ukuran butir lempung tersebut menjadi tidak seragam. Kandungan fragmen Kuarsit tersebut dapat menimbulkan retakan pada gerabah yang telah telah dikeringkan dan dibakar. Masalah ini dapat diatasi dengan membuang fragmen kuarsit dari agregat lempung sebelum diolah menjadi gerabah.

b. Sebagai bahan industri farmasi dan kosmetik

Industri farmasi membutuhkan banyak bahan yang berasal dari mineral lempung, diantaranya Kaolinit, Smektit, Sepiolit, Paligorskit, dan lain-lain. Lempung yang dijumpai di Perbukitan Jiwo adalah Kaolinit, Smektit, dan Serisit. Kaolinit digunakan sebagai pelindung lambung, anti diare, anti inflamasi, dan bius lokal, sedangkan Smektit digunakan sebagai bahan 


\section{Teknik, 38 (2), 2017, 69}

antasida pelindung lambung, dan anti diare (Carretero, Pozo, 2009).

Kaolin, Smektit dan Serisit dapat dimanfaatkan dalam industri kosmetik. Sifat khusus lempung yang diperlukan dalam industri kosmetik tersebut meliputi sifat fisik (ukuran dan bentuk butir lempung), luas permukaan, tekstur, warna dan tingkat kecerahan, serta karakteristik kimia yang meliputi luas permukaan kimia dan muatan ion (Lopez-Galindo, Viceras, Cerezo, 2007).

Dalam industri kosmetik, Kaolin digunakan sebagai bahan krim kosmetik, pelindung kulit, bedak dan emulsi; Smektit digunakan sebagai krim kosmetik, pelindung kulit, bedak, emulsi dan masker; sedangkan Serisit digunakan sebagai bahan krim kosmetik, bedak dan emulsi (Carretero, Pozo, 2009). Pemanfaatan lempung dalam industri farmasi kosmetik dan farmasi harus memenuhi spesifikasi kandungan kimia tertentu, seperti dapat dilihat pada Tabel 2.

Tabel 2. Perbandingan antara spesifikasi kadar kimia mineral lempung dalam industri farmasi dan kosmetik (Lopez-Galindo, Viceras, Cerezo, 2007) dengan kadar kimia lempung daerah penelitian

\begin{tabular}{clcccccc} 
No & Oksida & $\begin{array}{c}\text { Kaolinit } \\
(\%)\end{array}$ & $\begin{array}{c}\text { Smektit } \\
(\%)\end{array}$ & $\mathbf{A}$ & $\mathbf{B}$ & $\mathbf{C}$ & $\mathbf{D}$ \\
\hline 1 & $\mathrm{SiO}_{2}$ & $44,6-46,4$ & $51,2-65$ & 49,69 & 43,43 & 37,19 & 45,36 \\
2 & $\mathrm{Al}_{2} \mathrm{O}_{3}$ & $38,1-39,6$ & $15,2-34$ & 22,03 & 28,98 & 19,14 & 22,45 \\
3 & $\mathrm{Fe}_{2} \mathrm{O}_{3}$ & $0,1-0,2$ & $0,1-7,4$ & 7,69 & 11,56 & 13,19 & 9,45 \\
4 & $\mathrm{TiO}_{2}$ & $0,1-0,2$ & $0-13,6$ & 0,86 & 1,13 & 1,30 & 0,92 \\
5 & $\mathrm{CaO}$ & $0,1-0,2$ & $0-4,2$ & 0,36 & 0,29 & 0,82 & 0,77 \\
6 & $\mathrm{MgO}$ & $0-0,1$ & $0-3,7$ & 1,21 & 1,38 & 0,33 & 1,12 \\
7 & $\mathrm{~K}_{2} \mathrm{O}$ & $0-0,2$ & $0-1,8$ & 2,84 & 0,07 & 0,26 & 0,39 \\
8 & $\mathrm{Na}_{2} \mathrm{O}$ & $0-1,4$ & $0-0,13$ & 0,58 & 0,06 & 0,16 & 0,91 \\
\hline $\mathrm{K}$ & & & & & &
\end{tabular}

Keterangan:

$A=$ Lempung Pager Jurang (Kaolinit, smektit)

$\mathrm{B}=$ Lempung Gunung Sari (kaolinit)

$\mathrm{C}=$ Lempung Gunung Konang (kaolinit, smektit)

$\mathrm{D}=$ Lempung Gunung Gajah (kaolinit, smektit)

Dari tabel perbandingan tersebut dapat dilihat bahwa kadar kimia lempung di daerah penelitian, baik Kaolinit maupun Smektit, tidak memenuhi spesifikasi untuk digunakan dalam industri farmasi dan kosmetik.

c. Sebagai bahan industri kertas

Mineral lempung yang dapat digunakan dalam industri kertas adalah Kaolin. Kaolin bisa digunakan sebagai bahan pelapis dan pengisi, bila memiliki tingkat kecerahan yang tinggi dan tingkat abrasi yang rendah (Ciulli, 1996).

Lempung yang akan digunakan dalam industri kertas harus memenuhi spesifikasi kandungan kimia tertentu, seperti dapat dilihat pada Tabel 3. Tabel 3 menunjukkan bahwa kadar kimia lempung di daerah penelitian tidak memenuhi spesifikasi untuk digunakan dalam industri kertas, baik sebagai bahan pelapis maupun pengisi.

Tabel 3. Perbandingan spesifikasi Kaolinit dalam industri kertas (Suhala, Arifin, 1997) dengan Kaolinit di daerah penelitian

\begin{tabular}{llcccccc}
\hline No & Oksida & $\begin{array}{c}\text { Bahan } \\
\text { Pelapis } \\
(\boldsymbol{\%})\end{array}$ & $\begin{array}{c}\text { Bahan } \\
\text { Pengisi } \\
(\boldsymbol{\%})\end{array}$ & $\mathbf{A}$ & $\mathbf{B}$ & $\mathbf{C}$ & $\mathbf{D}$ \\
\hline 1 & $\mathrm{SiO} 2$ & 46,73 & 47,80 & 49,69 & 43,43 & 37,19 & 45,36 \\
2 & $\mathrm{Al} 2 \mathrm{O} 3$ & 37,84 & 37,30 & 22,03 & 28,98 & 19,14 & 22,45 \\
3 & $\mathrm{Fe} 2 \mathrm{O} 3$ & 0,92 & 0,52 & 7,69 & 11,56 & 13,19 & 9,45 \\
4 & $\mathrm{TiO} 2$ & 0,09 & 0,04 & 0,86 & 1,13 & 1,30 & 0,92 \\
5 & $\mathrm{CaO}$ & 0,05 & 0,20 & 0,36 & 0,29 & 0,82 & 0,77 \\
6 & $\mathrm{MgO}$ & 0,06 & 0,10 & 1,21 & 1,38 & 0,33 & 1,12 \\
7 & $\mathrm{~K} 2 \mathrm{O}$ & 1,70 & 1,72 & 2,84 & 0,07 & 0,26 & 0,39 \\
8 & $\mathrm{Na} 2 \mathrm{O}$ & 0,07 & 0,05 & 0,58 & 0,06 & 0,16 & 0,91 \\
9 & $\mathrm{LOI}$ & 12,33 & 12,30 & - & - & - & - \\
\hline
\end{tabular}

Keterangan:

$A=$ Lempung Pager Jurang (Kaolinit, smektit)

$\mathrm{B}=$ Lempung Gunung Sari (kaolinit)

$\mathrm{C}=$ Lempung Gunung Konang (kaolinit, smektit)

$\mathrm{D}=$ Lempung Gunung Gajah (kaolinit, smektit)

\section{Kesimpulan}

Berdasarkan hasil analisis yang dilakukan dalam penelitian ini, dapat disimpulkan bahwa jenis mineral lempung yang dijumpai di Perbukitan Jiwo adalah Kaolinit, Smektit dan Serisit. Berdasarkan kandungan mineral yang ada, direkomendasikan untuk memanfaatkan lempung di perbukitan Jiwo untuk bidang industri gerabah, namun tidak untuk bahan industri farmasi, kosmetik, dan kertas.

\section{Daftar Pustaka}

Carretero, M.I., Pozo, M. (2009). Clay and non-clay Minerals in the Pharmaceutical and Cosmetic Industry Part II Active Ingredients. Applied Clay Science, 47, 171-181.

Ciulli, P.A. (1996) Industrial Minerals and Their Uses, A Handbook \& Formulary. New Jersey: Noyes Publications.

Hastuti, I. (2009). Perkembangan Usaha Industri Kerajinan Gerabah, Faktor yang Mempengaruhi dan Strategi Pemberdayaan pada Masyarakat di Desa Melikan Kecamatan Wedi Kabupaten Klaten. Thesis. Surakarta: Program Pascasarjana Universitas Sebelas Maret.

Lopez-Galindo, A., Viseras, C., Cerezo, P. (2006). Compositional, Technical and Safety Specifications of Clays to be used as Pharmaceutical and cosmetic products. Applied Science, 36, 51-6

Rollinson, H. (1993) Using Geochemical Data : Evaluation, Presentation, Interpretation. United Kingdom: Longman Group. 
Teknik, 38 (2), 2017, 70

Smoot, T.W. (1961) Clay Minerals in The Ceramic Industries. Clays and Clay Minerals, 10(1), 309317.
Suhala, S. dan Arifin, M. (1997). Bahan Galian Industri. Bandung: Pusat Penelitian dan Pengembangan Teknologi Mineral. 